\title{
DIVULGAÇÃO DO DISCURSO POLÍTICO: AS METÁFORAS DE LULA E SUAS FORMAS DE INTERDIÇÃO
}

\begin{abstract}
Andréia da Silva Daltoé *
Resumo: A partir dos pressupostos teóricos da Análise do Discurso de linha francesa pêcheuxiana, analisaremos, no presente estudo, as formas de divulgação das metáforas de Lula (ML) pela mídia, durante o periodo em que Lula ocupou a função de Presidente do Brasil - os mandatos de 2002/2006 e 2006/2010. Para isso, organizamos nosso corpus por recortes de revistas e de jornais que se propuseram a divulgar as ML no espaço-tempo em questão, a fim de investigar por que os sentidos atribuidos a estes dizeres, em sua maioria, os deslocam para o espaço do erro, do desvio, do absurdo e da ignorância. Nossa proposta é observar se este estranbamento em relação às $M L$ representa o sintoma de um incômodo causado pela mexida que este funcionamento discursivo vai causar nos sentidos estabilizados da lingua política, cuja divulgação pela mídia se construirá enquanto interpretação única e possivel.

Palavras-chave: Discurso Político. Metáforas de Lula. Mídia.
\end{abstract}

\section{INTRODUÇÃO}

Eu fui comer pão, a primeira vez, com sete anos de idade. Eu sou de uma terra onde, se as pessoas não morrem até completar um ano de idade, já é um milagre. E eu não morri, cheguei a Presidente da República. (Lula, 2003)'.

Durante os dois mandatos em que Lula esteve na Presidência do Brasil, de 2002 a 2006 e de 2006 a 2010, chamaram-nos a atenção os efeitos de sentido produzidos pela mídia a respeito de seu discurso, em especial ao divulgar/significar o que estamos aqui designando por Metáforas de Lula (ML).

No trabalho de divulgação desse discurso, e aqui nos restringiremos a revistas e jornais de circulação no Brasil, interessamo-

\footnotetext{
* Doutora em Teorias do Texto e do Discurso (UFRGS-2011). Docente do Programa de Pósgraduação em Ciências da Linguagem da Universidade do Sul de Santa Catarina (UNISUL). E-mail: andreia.daltoe@unisul.br

${ }^{1}$ Trecho de entrevista concedida por Lula no Fórum de Davos/Folha Online, 26/01/2003. Disponível em: <http://www1.folha.uol.com.br/folha/brasil/ult96u45213.shtml>. Acesso em: 28 mar. 2010.
} 
nos, então, pelo modo como a mídia produziu, durante este espaçotempo, determinados sentidos e interditou outros, apresentando-os como uma interpretação única e possível do discurso de Lula (DL).

Pelo fato de que os sentidos oferecidos por tais formas de divulgação apontavam, em sua maioria, para um estranhamento no funcionamento do discurso político, é que passamos a supor que as ML provocaram uma forte mexida no ideal de língua política no Brasil, cujos sentidos se dão como consolidados/normatizados.

Procurando, então, investigar que sintomas o estranhamento em relação às ML encobre, a partir do campo teórico da Análise do Discurso (AD) de linha francesa pêcheuxiana, é que nos desafiamos a inquietações como: a) Por que tal estranhamento em relação ao modo de enunciar a lingua política pelas ML?; b) Há algo nesse funcionamento que ameaça/desinstala determinados saberes?; c) O que faz das ML um modo particular de enunciar do DL?; d) A rejeição às ML reside no fato de um Presidente usar metáforas ou nos conteúdos que elas veiculam?

\section{A INSCRIÇÃO NO CAMPO DO DISCURSO POLÍTICO}

Este trabalho insere-se no campo do político e, com isso, já recobra uma memória em relação aos primeiros estudos de $\mathrm{AD}$ na década de 60/70, que, conforme Pêcheux, em prefácio a Jean-Jacques Courtine (2009), tinha como proposta, desde suas origens na França, “eleger como objeto de estudo os 'discursos políticos' (mais frequentemente os de esquerda) para auscultar suas especificidades, alianças e demarcações" (2009, p. 22-23), como uma tentativa de alcançar um novo modo de leitura, a partir de determinada legitimidade científica que garantisse à área seu espaço de novo campo do saber.

Para responder a esta necessidade e a este momento, Pêcheux escreve a obra fundadora Análise Automática do Discurso (AAD69) ([1969] 1997) com o objetivo de, nas palavras de Henry, "fornecer às ciências sociais um instrumento científico de que elas tinham necessidade, um instrumento que seria a contrapartida de uma abertura teórica em seu campo" (HENRY, 1997, p. 15). Vale dizer que este momento coincide com o surgimento dos primeiros algoritmos de tratamento de texto, que permitiriam a elaboração de métodos de análise automática do discurso. 
Para Pêcheux, este projeto nascia, como expressa Gadet, "na crença em uma visão de intervenção política, porque aparece como portadora de uma crítica ideológica apoiada em uma arma científica, que permitiria um modo de leitura cuja objetividade seria insuspeitável" (GADET, 1997, p. 8).

Para Courtine (2006), esta proposta inicial da AD nasceu em torno da opacidade dos discursos políticos, como simulação, mentira e sedução, propondo-se a construir, segundo o autor, equivocadamente,

uma máquina de ver, isto é, de ler, uma montagem ortopédica de dispositivos técnicos que realizam praticamente e, literalmente, no próprio lugar do leitor, uma 'leitura não subjetiva' que, tirando a ambigüidade do texto, converta a opacidade em transparência, desfaça a mentira ou a sedução escondidas nas palavras, assegurando o retorno à clareza do discurso, reaparição de sua verdade, revelação de seu real. (2006, p. 20, grifo do autor).

Todavia, considerando, conforme Courtine (2006), que a AD "não constitui simplesmente uma aparelhagem técnica, mas igualmente um modo de intervenção política" (2006, p. 15), reconhecemo-nos nas palavras de Mazière, para quem "o analista de discurso não é uma pessoa neutra” (2007, p. 23), pois, em AD, não há espaço para neutralidade. De qualquer maneira, ao tratar do discurso político, ou melhor, de um discurso político em específico como as ML, há sempre um risco entre o tratamento teórico a se realizar e as identificações pessoais que atravessam a pesquisa, já que, conforme Pêcheux, "no se puede pretender hablar de discursos políticos sin tomar posición simultáneamente, en la lucha de clases, ya que esta toma de posición en realidad determina el modo de concebir las formas materiales concretas bajo las cuales las ideas entran en lucha en la historia" (1980, p. 182).

A respeito deste comprometimento, ensejamos certo equilíbrio entre um lugar e outro, considerando que, em $\mathrm{AD}$, a escolha do corpus e a maneira como ele engendra os procedimentos metodológicos já implicam uma posição, um gesto do analista, motivo pelo qual, neste campo do saber, não se pode falar em um modelo de análise predeterminado, que possa ser aplicado a todo tipo de corpus, mas em uma metodologia que vai sendo construída à medida que se vão costurando aspectos teóricos que têm a ver com os objetivos do analista.

DALTOÉ - Divulgação do discurso político... 
Esta proposta desfaz, portanto, a ideia de um corpus fechado e homogêneo do início da AD na França, conforme Mazière (2007), "construído como conjunto de dados prévios, feito de discurso doutrinal contrastado, produto de condições de produção controláveis e tomado em um ritual bem particular" (2007, p. 59), para oferecer ao discurso político um tratamento teórico a partir das práticas discursivas que este funcionamento do político coloca em jogo.

Diante desta mudança de tratamento de um corpus, o discurso político passa a ser pensado não como uma simulação capaz de ser desmascarada, descortinada, e sim como algo próprio da constituição de todo discurso. É porque os discursos não se dão em evidência, pelo modo como a língua não reflete a realidade, que é preciso investigar seus modos de funcionamento, procurando observar como eles fazem trabalhar os sentidos, e não como, ou se, eles escondem seus sentidos.

Tais deslocamentos foram pensados pelo próprio Pêcheux, conforme é possível observar em Prefácio a Courtine: "Fazer análise do discurso não seria, de fato, pressupor uma falta (uma deficiência, carência ou paralisia) que afeta a prática 'natural' da leitura e da escrita políticas, a qual uma prótese teórico-técnica, mais ou menos sofisticada, pretenderia preencher?" (2009, p. 22). Pêcheux vai chamar de imbecilidade essa ansiedade de preencher uma lacuna deixada pelas teorias positivistas, que se resume em dois equívocos: assumir uma posição diante do fantasma da objetividade, que impede de pensar o sentido sob a textualidade; ou assumir uma posição partidária cientificamente firmada, tendendo a tratar os nativos da política como imbecis. Para Courtine (2006), o que Pêcheux denominou "a imbecilidade dos selvagens da política" diz respeito à procura que havia, no início da $\mathrm{AD}$, por essa prótese linguística realizada por uma pedagogia da verdade (2006, p. 14).

Buscar a verdade por detrás de tais práticas de leitura seria buscar preencher um buraco, enxertando nele sentidos desvendados, como se fosse possível encontrar as palavras que se escondem, por isso a pergunta pertinente e inquietante de Pêcheux é: que falta é preciso exorcizar por meio de dispositivos de leitura? Está se pensando em descobrir o que se esconde atrás do que se diz? 
Podemos dizer que a tentativa de encontrar essas próteses que preencheriam os vazios pode ser observada em muitas das críticas em torno das ML pela mídia, cuja polêmica se dá justamente a respeito desse algo de objetividade que faltaria ao DL, desse algo que se esconderia atrás de suas palavras e que as metáforas vêm ocultar. Para nós, as ML são pistas para examinar o funcionamento do DL, e não um algo a se desvendar de determinado "ocultamento". Dito de outra forma: não estamos em busca dos sentidos que essa materialidade esconde, nem, portanto, em busca de próteses de leituras que preencheriam essa falta, como um enxerto abrigado na literalidade dos sentidos, pois sabemos que a falta em AD é constitutiva da linguagem e, deste modo, também o é nas ML. Nossa busca é pelos sentidos que esta materialidade discursiva produz e a que constituição sócio-histórico-ideológica aponta.

É nesta perspectiva que se compreende o corpus desta pesquisa que, formado por um conjunto de Sequências Discursivas de Referência (SDRs) colhidas de jornais e resvistas de circulação brasileira, vai representar os efeitos de sentido produzidos pela grande mídia a respeito das ML. São estes efeitos de sentido que procuraremos, em nossa análise, de-superficializar (PÊCHEUX; FUCHS, 1997), para, deste modo, questioná-los em suas formas de interpretação única.

Vale ressaltar que, neste recorte de revistas e jornais impressos e on-line, serão enumerados dizeres sobre o DL, considerando que, já no seu modo de registro impresso, encontramos formas de interdição deste discurso, causadas pela transcrição de um dizer por outro. Ou seja, não só a análise realizada pela mídia sobre o DL o nega como forma de dizer, mas a própria transcrição desse discurso faz trabalhar a dificuldade de sua aceitação.

Os dois registros, a seguir, de uma mesma ML podem representar esta questão, tratando-se do episódio no qual Lula disse, dezembro de 2009, que iria "tirar o povo da merda",

Jornal O Globo: Eu quero é saber se o povo está na merda e eu quero tirar o povo da merda em que ele se encontra. Esse é o dado concreto. (Lula, 11/12/2009).

Revista Época: Quero tirar o povo da m... em que ele se encontra. (Lula, 21/12/2009).

DALTOÉ - Divulgação do discurso político... 
Conforme observamos nestas duas materialidades, a fala de Lula sofre uma intervenção/interdição na forma de seu registro, o que significa que, quando sua fala é apresentada pela/na mídia impressa, precisamos considerar que, mesmo entre aspas, esse dizer sofre as determinações e as condições de produção (CP) de cada suporte. Tais condições representam, conforme Courtine (2009), as "relações de lugar que remetem a relações de classe, isto é, a um dado estado das contradições ideológicas de classe em uma conjuntura histórica" (2009, p. 108).

Neste caso, só pelo registro do "palavrão" de Lula (como foi designado nessa reportagem de $O$ Globo), que ora aparece como merda e ora como um m-reticências, já se tem uma amostra do funcionamento de diferentes materialidades com as quais teremos que, inevitavelmente, lidar neste estudo, marcadas por interditos e atravessamentos e observadas pelas marcas das condições em que se produzem.

Como observamos nos dois exemplos anteriores, pelo registro da própria fala de Lula e pelo impresso dessa fala, será necessário considerála sempre a partir de suas CP, pressupondo que a língua traz em seu interior elementos sócio-históricos que a atravessam constitutivamente. No caso das ML, tais condições não dizem respeito, porém, apenas ao tipo de suporte do qual as sequências são retiradas, mas, principalmente, aos interesses a que os meios de comunicação no Brasil correspondem, em condições tais que, segundo Neto (2003, p. 125):

o 'ato enunciativo' não é compreendido como 'atividade livre' em que os sujeitos constroem, seja lá como for, suas possibilidades de sentidos. Pelo contrário, ele se faz mediante determinadas condições definidas pelas negociações que tais campos sociais realizam para operar a produção de discursos.

Sendo assim, para conceber as ML e seus efeitos de sentido a partir do suporte em que aparecem, precisamos sempre lembrar que, nas condições normais do modo de produção capitalista, a mídia serve aos objetivos das classes que a mantêm, correspondendo, deste modo, conforme Rubim (2000), à lógica dos interesses mercantis e publicitários, do sistema capitalista em geral e dos anunciantes, dos interesses de Estado e de governos, enfim, à lógica produtiva do espetáculo e a outras lógicas de produção. 
Todavia, conforme o autor, mesmo que essas limitações interfiram na relação mídia/política, não se pode dizer que isso signifique a supremacia de uma lógica de espetacularização do discurso político, sem que trabalhe aí uma dinâmica própria da política. Ou seja, para Rubim (2000, p. 72), “a espetacularização pode significar a realização e dominância de uma lógica midiatizada ou, pelo contrário, a predominância de uma lógica política que se realiza junto, através do recurso ao espetacular midiatizado". Por isso, também conforme o autor:

as afirmações dogmáticas e preguiçosas devem ceder lugar ao trabalho investigativo que busca analisar detidamente e sem preconceitos as conexões, complementares ou conflituosas entre política, mídia e espetacularização, sempre e obrigatoriamente inscritas em campos de força determinados, somente nos quais eles ganham efetividade societária. (2000, p. 72).

Procurando, então, não nos cegar pela divulgação do discurso político como uma verdade única e possível, é que seguimos nosso trabalho em busca de uma possibilidade de de-superficialização de tais "evidências".

\section{DIVULGAÇÃO DAS ML: EM DEFESA DE UM IDEAL DE LÍNGUA POLÍTICA}

Durante os oito anos em que esteve na Presidência do País, Lula foi notícia pelo que fez e, muito, pelo que falou. Para a mídia e para o meio intelectual em geral, as ML se transformaram em uma característica do DL, um jeito de falar, um tipo de estilo, a ser investigado, analisado e, até mesmo, desvendado. Esses gestos de leitura foram significando, no decorrer dos dois mandatos, as ML no cenário da política nacional como um problema, o que as SDRs abaixo, representativas de títulos de reportagens a respeito, podem mostrar:

SDR1: Metáforas do presidente contaminam fala dos ministros (Folha de S. Paulo, 28/12/2003). 
SDR2: Haja paciência (Folha de S. Paulo, 23/08/2003).

SDR3: Lula voa em metáforas: a linguagem figurada popularesca do Presidente da República tende a desgastar seu discurso paternalista (Revista Lingua, 2005).

SDR4: Todas as metáforas do presidente (Gazeta do Povo, 06/09/2009).

SDR5: Lula e suas metáforas: Presidente foge do compromisso com as palavras ao abusar das figuras de linguagem em seus discursos (Revista Lingua on line, 2010).

Estas SDRs exemplificam o quanto o uso de metáforas por Lula chamou a atenção de intelectuais, políticos e jornalistas, os quais procuraram, em sua maioria, deslocar o funcionamento deste discurso para a ideia de erro, desvio, ignorância, etc. Por isso, julgamos que o debate em torno das ML atua, comumente, como formas reguladoras do discurso político, tentando tirá-lo, conforme Gadet e Pêcheux (2004, p. 115), de uma espécie de "espaço completamente exterior, lugar do ilógico e do não formulável, em que a 'poesia' e a 'loucura' combinam seus poderes". Nessa ideia de cruzada em torno das ML ou do que elas representam, o uso de metáforas pelo, à época, Presidente deixa de importar pelos sentidos que mobilizam e passam a valer como um modo ilógico, estranho, inadequado de falar a língua política.

No caso da SDR1, este jeito estranho de falar aparece como uma contaminação de linguagem, considerando que os ministros também estariam falando em metáforas como Lula.

Do texto apresentado pelo título da SDR5, em que as ML aparecem como fuga, ignorância, destacamos a seguinte SDR, em que Demétrio Magnoli, doutor em geografia humana pela USP,

SDR6: [...] irrita-se com o discurso político escorregadio: - O divórcio entre palavra e fato é sempre a melhor evidência da renúncia ao realismo (2010). 
Também no mesmo texto mencionado pela SDR5, para a professora de jornalismo e cientista política da Universidade do Estado do Rio, Alessandra Aldé, a respeito das ML,

SDR7: [...] usar figuras de linguagem é uma saída para quem não quer ser cobrado pelo que diz. - Quando se usa uma metáfora, tem-se um grau menor de compromisso com a realidade. Não dá para as pessoas cobrarem objetivamente um discurso metafórico (2010).

A SDR\& vai, portanto, apontar as ML como recurso de linguagem, para demonstrar o descompromisso de Lula com o que diz, bem como para mascarar as mudanças pelas quais seu discurso foi sofrendo na transição de ex-operário a Presidente do País.

Ainda no mesmo texto, para o sociólogo Edmundo Fernandes Dias (Unicamp),

SDR8: [...] as metáforas apenas anunciam o que [Lula] não pode enunciar claramente: 'a mutação'. Juízos severos, que demonstram decepção e impaciência". [...] exageros à parte, a verdade é que algumas dessas metáforas não passam de fórmulas prontas. Compõem um arsenal que quase sempre dispensa o esforço de pensar e articular o discurso apropriado, preciso, para a situação.

No texto de "Haja paciência", SDR2, para Clovis Rossi, as ML contribuem para tornar Lula um sujeito folclórico, já que o uso abusivo desse recurso o leva a ser ridicularizado em programas humorísticos. Do dizer de Rossi, destacamos a seguinte SDR:

SDR9: [...] a folclorização corrói lenta, mas mortalmente a imagem [Lula]... algumas até são boas, mas a grande maioria, convenhamos, não diz nada ou é pura bobagem (2003). 
É neste mesmo sentido que, do texto "Lula voa em suas metáforas" (SDR3), assinado por Josué Machado, recortamos a SDR a seguir:

SDR10: [...] o discurso improvisado de Lula é colorido, ilustrado, mas tende a ser pobre, muito pobre [...]. Um verdadeiro pulo, digo, vôo de galinha. Começa aqui e cai ali. Não chega jamais aonde o autor imaginou que poderia chegar. (2005, p. 43).

A SDR10 mostra como os sentidos atribuídos às ML pela mídia apontam este modo de dizer como refúgio do Presidente por não querer assumir suas palavras, ou mesmo como reflexo de sua ignorância frente aos problemas da política no Brasil, deslocando, deste modo, a discussão sobre o que essa materialidade representa na política brasileira para o terreno do desprestígio e da ignorância.

Esta ideia de erro no modo de dizer a língua política, em outras situações de divulgação deste discurso, também vai aparecer como uma habilidade argumentativa de Lula, o qual passa a ser, então, considerado como um estrategista de seu discurso, um exímio orador que, de forma engenhosa, arquitetaria seu discurso com fins precisos e calculáveis, conforme exemplifica a SDR a seguir, em que, para Paulo Bearzoti Filho, em $A$ voz do Brasil, os:

SDR11: [...] 'erros' remanescentes na fala do presidente comporiam antes uma estratégia deliberada para facilitar a identificação com as camadas pobres da sociedade.

No caso da SDR 11, o sujeito enunciador deste discurso é compreendido como aquele que domina seu discurso e que, se comete algum erro de português, o faz propositalmente. Trata-se, portanto, de um sujeito que domina a língua e os sentidos que ela deve alcançar em seu processo de interlocução.

$\mathrm{O}$ que podemos verificar também nesse efeito de sentido da ML, quando tomada como recurso estilístico ou como recurso estratégico, são sintomas de um forte estranhamento em relação ao modo de falar de 
Lula, que passa a significar um modo impróprio, não protocolar, desviante do que seria o adequado a um Presidente da República.

Um outro efeito de sentido da ML produzido pela mídia remete à abordagem humorística desse discurso, cujo exemplo é tomado do livro Nunca antes na história deste país de Marcelo Tas (2009). O livro apresenta frases, conforme o autor, engraçadas e polêmicas do Presidente Lula, cujo prefácio, escrito por José Simão, já antevê o tom da pesquisa:

SDR12: E o Brasil é lúdico. E o Lula é zeroglota! O FHC era poliglota, o Itamar, monoglota, e o Lula, zeroglota. Não fala língua nenhuma. Aliás, minto, ele fala quatro: o lulês, o churrasquês, o futebolês e o butequês! O LULA É TETRALÍNGUE! UEBA! (2009, p. 8).

Em tom depreciativo, a obra categoriza o DL a partir de um Lula advogado, Lula animal politico, Lula economista, Lula marqueteiro, etc., num trabalho que escande a fala de Lula a partir do objetivo do humor, afastando-a de qualquer implicação/constituição sócio-histórica, já que, nas palavras de Tas, Lula surgiu:

SDR13: [...] como um personagem de videogame, que salta abruptamente de uma fase para outra, o presidente Lula parece ter recebido todo conhecimento do mundo num único clique: quando recebeu a faixa presidencial! Como num passe de mágica, o ex-metalúrgico tomou posse, não apenas da Presidência da República, mas de toda sabedoria e diplomas acadêmicos aos quais não teve acesso antes. (2009).

Também aqui podemos perceber o quanto do DL provoca estranhamento, mobilizando discussões que apontam para efeitos distintos, o do humor, mas que não deixam de mostrar que algo incomoda, que algo se desinstala no discurso político a partir daí.

Um exemplo distinto, talvez, seria a obra de Ali Kamel (2009): Dicionário Lula: um presidente exposto por suas próprias palavras, que, embora pressuponha um sujeito consciente de seu discurso, não procura 
desmerecer Lula pelo seu modo de dizer. O Dicionário é composto de 347 verbetes, que foram sendo coletados com a ajuda de softwares de pesquisa, especialmente elaborados para isto, e que, conforme o autor, ajudaram a compor o "léxico Lula".

Em comentário a essa obra, Ronaldo Azevedo, no site Veja on line (2009), resume o Dicionário dizendo que "É o verbo a espelhar o homem". Como dissemos anteriormente, tanto esta opinião quanto o título do dicionário supõem um sujeito cujas palavras o representam/revelam, o que pressupõe: a) um sujeito estrategista de seu discurso e, portanto, autônomo; b) uma língua que reflete em fidelidade o pensamento; e c) um sentido que, diante da autonomia do sujeito e da língua, admite controle.

Todavia, embora essa perspectiva de sujeito, de língua e de sentido, filiados a um mundo semanticamente estabilizado, aponte para uma certa regularidade entre o sujeito e seu discurso, bem como para sua autonomia em relação ao verbo, em Kamel (2009), observamos um efeito de sentido do DL um pouco diferente dos recortes anteriores, pois o autor não está diminuindo esse jeito de falar, pelo contrário, reconhece aí uma habilidade comunicacional, considerando que:

SDR14: [...] o método de Lula discursar' [...] é absolutamente consciente. [...] quase sempre Lula sabe o que faz, por que faz e onde faz. [...] Para isso, Lula transforma o que muitos veriam como deficiência - sua sintaxe popular e sua falta de sofisticação gramatical - numa poderosa arma de comunicação (2009, p. 23).

Sabemos que, para o campo teórico da $\mathrm{AD}$, não lidamos com um sujeito consciente de seu discurso, autônomo em relação às suas potencialidades discursivas, como pressupõe a obra de Kamel. Todavia, a construção deste Dicionário não deixa de apontar para um modo de funcionamento discursivo do DL distinto daquele observado anteriormente, em que, tentando desmerecer o modo de falar do então Presidente, procura diminuí-lo em sua importância como líder político.

Ao comentar seu Dicionário, em Gazeta do Povo on line (06/09/2009), Kamel afirma que: 
SDR15: [...] independentemente de eventuais erros e acertos verbais (do presidente), [Lula é um] comunicador sem igual [...] Pode-se discordar do que ele fala, mas não há como negar que ele se comunica com extrema competência (2009).

Kamel vai defender que uma das razões para essa boa performance de comunicação do presidente é justamente o uso das metáforas. Portanto, embora o sujeito desse Dicionário seja um sujeito estrategista, que não é o sujeito da $\mathrm{AD}$, a importância do trabalho de Kamel, ao tentar organizar esta fala em um dicionário, não deixa de apontar para a necessidade de se entender por que o DL se marca como um modo particular de enunciar, construindo-se aí uma diferença em relação ao discurso de outros presidentes.

Todavia, distanciando-se desta importância dada ao DL, a própria reportagem que trouxe a fala de Kamel, ao fim, arremata do seguinte modo:

SDR16: [...] além das metáforas, repetição, simplicidade, e mesmo alguns erros, são os ingredientes que fizeram do atual presidente essa espécie de esfinge, que ninguém ainda decifrou completamente - daí a relevância de trabalhos como esse, de Kamel, que ajudam a entender, e mesmo a desconstruir, o fenômeno chamado Lula (2009).

Ou seja, conforme a SDR16, ignora-se o dizer de Kamel sobre a importância de Lula como líder político e novamente se volta à ideia de relacionar as ML a algo que precisa ser decifrado - no modo de uma esfinge.

De qualquer maneira, embora a concepção de Kamel sobre a análise do DL se apoie sobre concepções estruturais de organização dessas falas, podemos dizer que, nesse Dicionário, se constroi também um discurso, pois, segundo Siveris et al. (2009), o dicionário pode se constituir em: 
um objeto discursivo, no qual o saber sobre a língua constitui-se, institui-se, organiza-se, reorganiza-se; bem como é retomado, é construído e é desestabilizado, produzindo efeitos de sentidos, sejam eles dados, postos, já-ditos ou novos, atualizados, reformulados (2009, p. 1-2).

Para as autoras, o dicionário representaria, então, um espaço de construção, desconstrução e reconstrução de sentidos, corroborando Orlandi, segundo a qual, o "funcionamento do dicionário se dá na relação do sujeito com a língua, incluindo sua relação com a memória discursiva" (2002, p. 103). Enfim, trata-se de uma lexicografia discursiva que vê, nesse tipo de obra, um discurso, já que,

na escuta própria à análise do discurso, podemos ler os dicionários como textos produzidos em certas condições tendo seu processo de produção vinculado a uma determinada rede de memória diante da língua (2002, p. 103).

Por este motivo, consideramos que a publicação desse Dicionário não apazigua a ansiedade de muitos em descobrir o que está por detrás das ML, mas, sem dúvida, representa um sintoma do quanto o DL desperta interesse e o quanto instiga a escrever a respeito.

\section{AS ML: UM MODO DE SUBVERSÃO DA ORDEM POLÍTICA NA LÍNGUA}

Para Zoppi-Fontana (no prelo), em seu estudo Lingua política: modos de dizer nal da política, os dois livros de que tratamos na seção anterior, Dicionário Lula e o Nunca antes na bistória deste país, apresentam-se como gestos de interpretação que, dada sua formulação como dicionário (no caso de Kamel) ou livro de citações (no caso de Tas):

produzem a estabilização de determinados sentidos que constituem imagens da língua política, e consequentemente, da língua-outra fantasmática, da qual se distancia ou se aproxima em movimentos de identificação e contraidentificação que constituem a enunciação política. 
Por isso, segundo Zoppi-Fontana, no caso das obras de Kamel e de Tas, não se trata de estudar o léxico político ou o fazer lexicográfico sobre esse campo discursivo, mas de apontar o modo como a língua política ganha existência e forma no acontecimento.

Entendemos, juntamente com Zoppi-Fontana (no prelo), que, no DL, uma língua política funciona:

como um modo de dizer produzido no exercício do poder, constitutivamente ligado a suas condições históricas de produção, que volta reflexivamente sobre si mesmo, tornando-se objeto explícito do confronto político tanto por aqueles que enunciam das instâncias próprias do campo da política, quanto por aqueles que produzem um discurso sobre essa língua (principalmente na mídia).

O que observamos comumente os discursos sobre as ML é que o julgamento deste modo de enunciar só pode ser pensado a partir do parâmetro de um ideal de língua política, cujo imaginário social a toma em sua regularidade, em sua normatização. Uma língua que, conforme Gadet e Pêcheux (2004), transforma-se em uma construção artificial de unidade, logicamente estabilizada por uma ordem política na língua (2004, p. 31), que vai tentar conter todas as formas de ameaça a essa organização normatizada.

É essa língua artificial, ritualística, que permite olhar as ML como desvio daquilo que deveria ser um discurso presidencial, transformandose, por isso, em um modo de subversão a essa regularidade. Somente em relação a essa língua fechada é que as ML se justificariam como um problema, já que, conforme Gadet e Pêcheux (2004), "uma problemática do distanciamento e do desvio só é concebível em relação a uma totalidade" (2004, p. 157).

Por isso, as ML podem ser entendidas, a partir de Zoppi-Fontana, como um desvio à imagem "de uma língua política 'ideal', que assombra, como língua-outra ou fantasmática, os embates ideológicos em torno do discurso político". Neste caso, as ML representariam o afastamento dessa língua fantasmática que prescreve o que deve/como deve enunciar um Presidente, língua esta que, para muitos, Lula não domina. 
Assim, quando afirmamos que as ML provocam estranhamento, este não se dá porque um Presidente se utiliza de determinada figura de linguagem, ou seja, não se dá pelo simples fato de Lula empregar metáforas em seu discurso, mas pelos conteúdos veiculados por elas sentidos estes que vão mexer com as formações imaginárias do que é ser um Presidente da República, o que é se portar como tal e o que deve ser ou não assunto de política.

Por exemplo, do texto Lula e suas metáforas, SDR5, recortamos:

SDR17: Numa das metáforas parabólicas, Lula comparou seu ministério (talvez o maior do universo, com 36 integrantes) a um time de futebol. Nele, Lula seria o técnico, isto é, o 'professor'. E Palocci, o eficiente goleiro (2010).

Conforme apresentamos anteriormente, a SDR17 aponta que o problema no DL não está exatamente em Lula usar metáforas em seu discurso, mas no fato de suas metáforas estabelecerem relação entre coisas que não seriam próprias à língua política, como, por exemplo, governo/time de futebol.

Com isso, podemos dizer que o estranhamento causado pelas ML, embora apareça sob as mais variadas justificativas - da pureza da língua à retidão protocolar de um Presidente -, acaba apontando para a maneira como os sentidos mobilizados por esse discurso incomodam, desestabilizam, por colocarem em relação coisas de esferas distintas (governo/futebol), como se isso fosse macular a língua política.

Deste modo, as ML passam a nos interessar enquanto processo discursivo que promove o deslizamento dos sentidos cristalizados da língua política brasileira para um novo modo de enunciar nessa cena discursiva, ao estabelecer relações entre sentidos da vida política e sentidos da vida comum, tais como:

a) porco/partidos oposicionistas: "Você não pode deixar de dar comida para um porco porque você não gosta do dono do porco" (Lula, 2010). 
b) futebol/religião/otimismo: "Tem gente que não gosta do meu otimismo, mas eu sou corintiano, católico, brasileiro e ainda sou presidente do País. Como eu poderia não ser otimista?" (Lula, 2009).

c) fome/religião: "Se fosse fácil resolver o problema da fome, não teríamos fome." [...] "Deus pôs os pés aqui (no Brasil) e falou: 'Olha, aqui vai ter tudo. Agora, é só homens e mulheres terem juízo que as coisas vão dar certo" (Lula, 2004).

d) eleições/futebol: "Vamos trabalhar para ganhar as eleições. Não é uma eleição fácil. É como time de futebol. Quando o time está ganhando de um a zero, de dois a zero, quando o time está ganhando, recua, não quer mais fazer falta, pênalti, fica só rebatendo a bola. E quem está perdendo vem para cima com tudo, e é com gol de mão, de cabeça, de chute, de canela. Não tem jogo ganho ou fácil” (Lula, 2010).

e) diarreia/mercado financeiro: "Quando o mercado teve a dor de barriga, que não foi uma dor de barrigazinha, foi uma diarréia daquelas, insuportável... Quando o mercado teve essa diarréia, quem é que eles chamaram para salvá-los? O Estado, que eles negaram durante 20 anos" (Lula, 2008).

É também a partir deste deslizamento de sentidos que, para nós, o funcionamento das ML desloca a noção de metáfora como espaço de similitude, tal como é concebida pelo senso comum, para a noção de metáfora como espaço de divergência. Ou seja, as ML vão trazer à tona relações de diferença, de divergência, e não de semelhança. Por isso, o funcionamento discursivo da ML desinstala a noção de metáfora em suas relações de similitude, para representá-la a partir das aproximações que estabelece entre sentidos divergentes, ou mesmo antagônicas.

Como podemos observar no funcionamento das ML, é esse deslizamento dos sentidos estabilizados da língua política para um novo modo de dizer, o qual tem a ver com as coisas simples do homem comum, que vai provocar uma mexida nas fileiras dos sentidos normatizados da política brasileira e causar o estranhamento sobre o qual discutimos neste texto. Estranhamento este que, na verdade, acaba encobrindo, para nós, a dificuldade de se aceitar que um homem sem estudos governe um país.

DALTOÉ - Divulgação do discurso político... 
Zoppi-Fontana (no prelo) nos ajudou a pensar a este respeito, considerando que o debate em torno do DL, num primeiro momento, dava-se sobre a adequação da língua de Lula à norma-padrão e ao registro formal, com clara predominância de sentidos desqualificadores, mas depois cede lugar a um debate sobre seu funcionamento retóricoreferencial, fazendo com que tais discursos configurem, "por delimitação, avaliação ou apagamento, diversas imagens de uma língua política 'ideal', que assombra, como língua-outra ou fantasmática, os embates ideológicos em torno do discurso político" (p. 5). Por este motivo, para Zoppi-Fontana, este modo de dizer de Lula:

deu lugar a um debate sobre a língua, não só em termos de adequação à norma padrão e ao registro formal (o que aconteceu nos primeiros anos do seu mandato com clara predominância de sentidos desqualificadores), mas principalmente em relação a seu funcionamento retórico-referencial: a descrição de o quê e o como dessa enunciação política, cujos contornos e inflexões tornaram-se objeto de análise para jornalistas e especialistas, e alvo preferido dos humoristas. (no prelo)

Ou seja, Lula passou a resolver os famosos "erros de Português", a colocar os esses e os erres no final das palavras e deixou de falar menas. A partir dessa "adequação" a uma língua oficial a que um Presidente deve obedecer, o atendimento às regras gramaticais do português não seria, então, mais o problema do DL. O problema passou a ser de uma outra ordem, residindo em torno dos sentidos que as ML veiculam.

\section{ALGUMAS COSTURAS}

Ao investigar o modo como a mídia significa as ML, foi possível observar que o incômodo provocado pelas ML está em relação aos sentidos que são mobilizados por esse discurso, os quais vão inserir, num ideal de língua política, sentidos próprios da cultura popular, do homem comum, fazendo falhar as coisas-a-saber-e-a-falar de um Presidente da República. 
Ou seja, as ML vão subverter um ideal de língua política por estabelecerem a relação na não-relação, trazendo à tona, neste cenário discursivo, as divergências que permeiam as relações sociais no País. E são os sentidos da vida simples, colocados em jogo neste funcionamento discursivo, que vão pôr em risco a língua fantasmática da política brasileira, perturbando nossas formações imaginárias a respeito.

Para nós, é por isso que as ML se constituem numa ameaça - por construírem, conforme Indursky, "um novo lugar político e um novo sujeito discursivo no cenário político brasileiro" (1999, p. 174). Cercear as ML passa, então, a ser necessário como forma, segundo Orlandi, "de se apagar sentidos, de se silenciar e de se produzir o não-sentido onde ele mostra algo que é ameaça" (2002, p. 14). Ou seja, levar as ML para o terreno do ilógico é silenciar o desarranjo de um ideal de língua política, que sempre lutará por defender a regularidade e a harmonia social enquanto silencia as relações antagônicas que permeiam a sociedade.

A partir dos sentidos produzidos pela mídia a respeito das ML, observamos esta cruzada em prol de um ideal de língua política, o que tem a ver com a luta por uma cultura autônoma, que, conforme De Nardi (2007), age enquanto unidade, tomada como parâmetro do que é apropriado ou não a determinados grupos sociais. Deste modo, as culturas se relacionam como blocos fechados em confronto e, como esta tensão não se resolve, segundo a autora, é "mais fácil acomodar-se em um dos extremos, negando o outro, provocando seu apagamento" (2007, p. 65).

É a partir desta ideia de cultura autônoma, que vai inferiorizar quaisquer outras possibilidades de cultura, que a mídia inscreve o DL, vigiando-o continuamente, como se o sujeito enunciador deste discurso estivesse sempre na iminência de constranger as pessoas pelos sentidos que emprega, impondo situações "delicadas" no espaço de polidez do discurso político.

É em nome desta cultura autônoma que as ML são negadas/ interditadas, como um modo de, segundo Gadet e Pêcheux ([1981] 2004), conter as formas de subversão na ordem da língua política, numa "incessante vigilância de tudo o que - alteridade ou diferença interna arrisca questionar a construção artificial de sua unidade e inverter a rede de suas obrigações" (2004, p. 31). 


\section{REFERÊNCIAS}

COURTINE, J.-J. Metamorfoses do discurso político: derivas da fala pública. São Carlos: Claraluz, 2006.

Análise do discurso político: o discurso comunista endereçado aos cristãos. São Carlos: EdUFSCAR, 2009.

DE NARDI. F. S. Um olhar discursivo sobre língua, cultura e identidade: reflexões sobre o livro didático para o ensino de espanhol como língua estrangeira, 2007. Tese (Doutorado em Teorias do Texto e do Discurso). Curso de Pós-Graduação em Letras, Universidade Federal do Rio Grande do Sul - UFRGS.

GADET, F. Prefácio. In: GADET, F.; HAK, T. (Orgs.). Por uma Análise Automática do Discurso. Uma introdução à obra de Michel Pêcheux. Campinas, SP: Ed. da UNICAMP, 1997.

GADET, F.; PÊCHEUX, M. A língua inatingível: o discurso na história da lingüística. Tradução de Bethania Mariani e Maria Elizabeth Chaves de Mello. Campinas: Pontes, 2004.

HENRY, P. Os fundamentos teóricos da "Análise Automática do Discurso" de Michel Pêcheux (1969). In: GADET, F.; HAK, T. (Orgs.). Por uma Análise Automática do Discurso. Uma introdução à obra de Michel Pêcheux. Campinas, SP: Ed. da UNICAMP, 1997.

INDURSKY, F. De ocupação a invasão: efeitos de sentido no discurso do/sobre o MST. In: __ _ LEANDRO-FERREIRA, M. C. (Orgs.). Os múltiplos territórios da Análise do Discurso. Porto Alegre: Editora Sagra Luzzatto, 1999.

KAMEL, A. Dicionário Lula: um presidente exposto por suas próprias palavras. Rio de Janeiro: Nova Fronteira, 2009.

MAZIÈRE, F. A análise do discurso: história e práticas. Tradução de Marcos Marcionilo. São Paulo: Parábola Editorial, 2007.

NETO, A. F.; VERÓN, E. (Orgs.) Lula presidente: televisão e política na campanha eleitoral. São Paulo: Hacker; São Leopoldo, RS: Unisinos, 2003.

ORLANDI, E. P. Língua e conhecimento lingüístico: para uma História da Idéias no Brasil. São Paulo: Cortez, 2002.

PÊCHEUX, M. Remontémonos de Foucault a Spinoza. Tradução de Miguel Rodríguez. In: TOLEDO, Mario Monforte (org.). El discurso político: teoria u 
análisis. Cidade do México: Universidad Nacional Autónoma de México y Editorial Nueva Imagem, 1980.

PÊCHEUX, M.; FUCHS, C. A propósito da Análise Automática do Discurso: Atualização e perspectivas (1975). Tradução de Péricles Cunha. In: GADET, F.; HAK, T. (Orgs.). Por uma Análise Automática do Discurso: Uma introdução à obra de Michel Pêcheux. Campinas, SP: Ed. da UNICAMP, 1997. RUBIM, A. A. C. Comunicação e política. São Paulo: Hacker Editores, 2000. SIVERIS, D.; RODIRGUES, N. R. L.; PETRI, V. Definição, descrição e nomeação em dicionários do século XIX. IV SEAD - Seminário de estudos em Análise do Discurso 1969-2009: memória e história na/da análise do discurso, 2009.

TAS, Marcelo. Nunca antes na história deste país. São Paulo: Panda Books, 2009.

ZOPPI-FONTANA, M. Língua política: modos de dizer na/da política (no prelo).

\section{REVISTAS E JORNAIS}

AZEVEDO, R. Veja on line. Disponível em: $<$ http://veja.abril.com.br/blog/reinaldo/geral/veja-8-o-dicionario-lula-de-alikamel/>. Acesso em: 15 fev. 2010.

Folha de S. Paulo, 28 dez 2003.

KAMEL, A. Gazeta do Povo. Disponível em: $<$ http://www.alikamel.com.br/upload/data/lula16.pdf>. Acesso em: 16 nov. 2010.

MACHADO, J. Lula voa em metáforas: a linguagem figurada popularesca do Presidente da República tende a desgastar seu discurso paternalista. Revista Língua, ano 1, n. 1, 2005.

O Globo on line. Lula usa palavrão para dizer que seu governo investiu mais em saneamento do que os anteriores (11/12/2009). Disponível em: $<$ http://oglobo.globo.com/pais/mat/2009/12/10/lula-usa-palavrao-paradizer-que-seu-governo-investiu-mais-em-saneamento-do-que-os-anteriores915141973.asp >. Acesso em: 20 fev. 2011.

Revista Época, 21/12/2009. 
Revista Língua. Disponível em:

$<$ http:/ / revistalingua.uol.com.br/textos.asp?codigo=10945>. Acesso em: 17 fev. 2010.

ROSSI, C. Haja paciência. Folha de S. Paulo. São Paulo, 23 ago. 2003.

\author{
Recebido em 20/10/11. Aprovado em 05/12/11.
}

Title: The divulgement of the political discourse: the metaphors by Lula and their forms of interdiction Author: Andréia da Silva Daltoé

Abstract: In this study the forms of divulging, by the media, the metaphors by Lula (ML) during the period of his presidency of Brazil (2002/2006 and 2006/2010) are discussed from the perspective of Discourse Analysis according to Pêcheux. Based on newspapers and magazines texts, which published the ML during that time/space, it is investigated how most of the meanings attributed to such sayings push them to the room of error, of deviation from the norm, of the absurd and of ignorance, indicating a sort of unfamiliarity in relation to the ML. In this work one observes if such a defamiliarization is a symptom of a shaking of the stabilized meanings of political discourse, while discussing how those meanings divulged by the media in relation to the ML are built as the only possible interpretation.

Keywords: Political discourse. Metaphors by Lula. Media.

Titulo: La divulgación des discurso politico: las metáforas de Lula y sus formas de interdicción Autor: Andréia da Silva Daltoé

Resumen: En El presente estudio se discuten, a partir de los supuestos teóricos del Análisis del Discurso de línea francesa pêcheuxiana, las formas de divulgación de las metáforas de Lula (ML) por los medios, durante el periodo en que Lula ocupó la función de Presidente de Brasil en dos mandatos: 2002/2006 y 2006/2010. A partir de recortes en revistas y periódicos que se propusieron a divulgar las ML en este espacio-tiempo, investigaremos el modo como la mayoría de los sentidos atribuidos a estos dichos lo disloca para el espacio del error, del desvio, del absurdo y de la ignorancia, apuntando para una especie de extrañeza en relación a las ML. Con este trabajo, procuraremos observar si esta extrañeza es sintoma de una revuelta en los sentidos estabilizados de la lengua política, discutiendo, para eso, como los sentidos vehiculados por los medios a respecto de las ML se construyen como una única interpretación posible.

Palabras-clave: Discurso político. Metáforas de Lula. Medios.

Linguagem em (Dis)curso, Tubarão, SC, v. 11, n. 3, p. 585-606, set./dez. 2011 